\title{
INVESTIGATION AND CONTROL OF REPRODUCTIVE DISORDERS IN THE BREEDING HERD
}

\author{
A.E. WRATHALL \\ Central Veterinary Laboratory, Ministry of Agriculture, Fisheries and \\ Food, Weybridge, Surrey, UK
}

At a national level there are unceasing efforts through research, technological innovation and education of producers to raise productivity of the pig industry to levels above the contemporary norm. Within this pace-setting framework the individual pig producer must set his own herd performance standard or target, and then try to maintain herd output as close as possible to that level with the greatest efficiency.

Performance standards in commercial herds include both physical and financial ones. However the latter, because they are so prone to market fluctuations beyond the producer's control, are less useful as criteria of efficiency. Some physical criteria which are extremely precise e.g. feed used per kilogram of pigmeat produced, or weaners (of defined age) per sow place per year, do emphasize important aspects of herd management and are dealt with in other chapters. In this Chapter attention is confined to the area of reproductive failure, i.e. failure by the breeding herd to reproduce adequate numbers of healthy newborn piglets within a specified time period. The term 'control' is used in the broad sense, i.e. any action which is taken to prevent, correct or reduce reproductive failure to a level where it no longer affects herd profitability.

It will be apparent from the foregoing remarks that, in the context of modern pig production, any distinction between control of overt diseases of reproduction (the traditional province of the veterinarian) and the control of reproductive failures arising from managemental inefficiency is very blurred. In the past the veterinary role tended to be of the "firebrigade' type, with intermittent responses to outbreaks of frank reproductive disease. This role is now changing rapidly with emphasis on closer and more regular involvement, not only with disease matters, but also with target setting, monitoring, stockmanship and many other aspects of herd management. Control of reproductive failure should, in fact, be seen as an integral part of the management process, the aim of which is to achieve and maintain a high level of herd health, performance and profitability. The principal steps involved in control of reproductive failure are shown in Figure 27.1 and it is these steps which are the main objects of discussion in this chapter. 


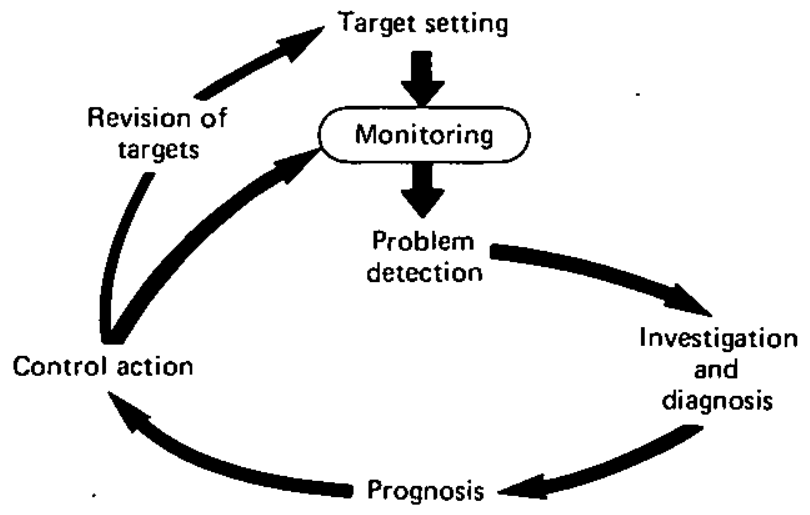

Figure 27.1 Flow diagram showing the principal steps involved in control of reproductive failure

\section{Target setting, recording and analysis of records}

The setting and periodic adjustment of herd performance targets are important preliminaries for effective control of reproductive failure. The overall target should be realistic and set with due regard to past performance of the herd as well as any aspirations based on published data from other herds of the same type. A guide to overall production standards is given in Table 27.1.

Although 'pigs reared per sow per unit time period' is the commonly used parameter for gauging overall herd performance, a useful criterion which relates more specifically to reproduction per se is 'liveborn piglets per sow per unit time' (LPSUT). Composite parameters like these are adequate by themselves only whilst the targets are being met or exceeded. When problems occur, and all herds do experience them from time to time, retrospective parameters like LPSUT are not suitable for early detection of trouble and are too general to pin-point exactly where in the reproductive cycle the failure lies. LPSUT, however, is composed of numerous subcomponents, each of which contributes positively or negatively to the

Table 27.1 OVERALL REPRODUCTIVE PERFORMANCE FIGURES EXPECTED FROM AN AVERAGE HERD PRACTISING 4-WEEK WEANING AND CULLING FEMALES AFTER AN AVERAGE OF FOUR LITTERS

\begin{tabular}{lccc}
\hline Output per female & \multicolumn{3}{c}{ Reference figure or standard } \\
\cline { 2 - 4 } & Gilts ${ }^{(4)}$ & Sows & All females \\
\hline Litters per year & 1.89 & 2.34 & 2.23 \\
Live piglets born per titter & 10.0 & 11.0 & 10.75 \\
Live piglets born per year & 18.90 & 25.74 & 24.00 \\
Live piglets born per month & 1.57 & 2.14. & 2.00 \\
\hline
\end{tabular}

(a)The term 'gilt' in this table refers to females (mated or unmated) which are over 6 months old but which have not yet weaned a litter. In some recording systems all females, once mated, arc referred to as 'sows', and virgin females intended for breeding are termed 'maiden gilts'. Under the latter system the number of live piglets born per 'sow' per year would be 25.47 ( 2.12 per month). 
Table 27.2 A GUIDE TO NORMAL REFERENCE FIGURES ('STANDARDS') FOR REPRODUCTION PARAMETERS, AND 'DECISION BOUNDARIES' ABOVE OR BELOW WHICH ACTIVE CONTROL MEASURES MAY BE NECESSARY

\begin{tabular}{|c|c|c|}
\hline Reproduction parameter & Reference figure or 'standard' & Decision boundary \\
\hline $\begin{array}{l}\text { Age at first service } \\
\text { Weaning-to-service interval } \\
\text { Regular returns ( } 21 \pm 3 \text { days) } \\
\text { Irregular returns ( }>24 \text { days) } \\
\text { Abortions } \\
\text { Failures to farrow (detected at term) } \\
\text { Farrowing rate } \\
\text { Piglets born alive per litter (gilts) } \\
\text { Piglets born alive per litter (sows) } \\
\text { Piglets born dead (stillborn) } \\
\text { Piglets born mummified } \\
\text { Smaller litter index } \\
(i)\end{array}$ & $\begin{array}{l}225 \text { days } \\
8 \text { days } \\
10 \% \\
3 \% \\
1 \% \\
1 \% \\
85 \% \\
9.5-10.0 \\
10.5-11.0 \\
5 \% \\
1.5 \% \\
12 \%\end{array}$ & $\begin{array}{l}>240 \text { days } \\
>12 \text { days } \\
>20 \% \\
>6 \% \\
>2.5 \% \\
>2 \% \\
\quad 80 \% \\
<9.0 \\
<10.0 \\
>7.5 \% \\
>3.0 \\
>25 \%\end{array}$ \\
\hline
\end{tabular}

(a)Small litter index $=$ percentage of litters which contain $\leqslant 8$ piglets (alive and dead).

overall figure (see column 3 of Table 27.2). Recording of these subcomponents or derivation of their values by the analysis of records is, therefore, very important for the effective detection of reproductive failure.

The mechanics of collecting records in the piggery is a complex topic and the systems used for it vary greatly from farm to farm depending on herd size and type, producer preference and other factors. Two important prerequisites for a good recording system are the standardization of terms and definitions, and the permanent and legible identification of breeding stock.

A recent booklet published by the Agricultural Development and Advisory Service in the UK (MAFF, 1979) gives a comprehensive list of terms and emphasizes the need for standardization, especially for computer-based recording systems. The booklet also describes pig identification methods. Practical aspects of recording are also discussed by Rodeffer, Leman and Mueller (1975), Muirhead (1978a) and Sundgren et al. (1980).

For obvious reasons the amount and types of data which are recorded routinely, and the level of sophistication in analysing them, tend to be proportional to herd size. For example, small herds with 20-30 sows need relatively little recorded information compared with those containing 200-300 sows where it is impossible for stockmen to remember many details about the performance of individual sows. Whilst most recording systems are designed to give information about whole-herd performance there is sometimes a need for more complex systems, such as systems which can carry the records of health and diseases of individual sows and boars as well as conventional reproductive data. These more complex individual-animal record systems, as well as whole-herd systems for the very large herd, really need to be computer-based if they are to be effective. Computers may appear at first sight to be an unnecessary extravagance, but when the time and labour costs of a manual system are taken into account this may not be the case. The real costs of computer equipment ('hardware') are declining, and good programmes ('software') specifically designed for herd recording purposes are rapidly becoming 


\section{Investigation and control of reproductive disorders in the herd}

available (MAFF, 1979; Pepper, Boyd and Rosenberg, 1977; Pepper, 1980; Walton, Martin and Ward, 1980; Wilson, McMillan and Swaminathan, 1980). Operating costs for computerized pig data systems in the UK are currently about $£ 5$ per month for whole-herd records, and $£ 2-3$ per sow per year for the individual-animal systems. It is not difficult to justify expenditure of this scale in many large herds because, as part of the herd health programme, it facilitates the raising of sow performance and consequently of herd profit margins.

Computer systems for herd recording utilize either the large 'mainframe' type of computer which is normally shared with many other users, and which is situated some distance away from the farm, or the 'mini' or 'micro' computer which is installed in the farm office or local veterinary practice. Transfer of data between the farm and mainframe computer can be by post, telephone, or by a terminal on the farm which is linked by telephone line directly to the computer. The postal system is, naturally, subject to delays but is less demanding in technological expertise than a terminal. The farm terminal system, however, like the mini or micro system, has the great advantage of allowing the herd manager or veterinarian to interrogate the computer himself, and to get immediate answers. Minicomputers suitable for most small businesses (like farms) now cost approximately $£ 3000-6000$, depending on requirements, and these figures do allow for necessary attachments such as a visual display unit (VDU) and a printer. Simple 'off-the-shelf' programmes may be included in the price but programmes specifically designed for analysis of pig herd records are still expensive and extra consultancy costs will probably be involved initially to ensure proper installation and operation.

An important but often overlooked component of herd recording is the inventory. To obtain this simply involves recording the numbers of adult males and females, and possibly the young stock, which are on the site at a particular moment. Ideally it is done regularly at the same time each week. Computers enable the inventory to be done extremely quickly and automatically, although sometimes a visual head count is worthwhile for validation purposes. The inventory contains essential raw data for calculating some of the important herd performance parameters, including LPSUT, and it will also show whether the farm is carrying its full complement of sows. The latter, of course, is vital if the return on capital expenditures such as buildings, land and labour, is to be maximized. If, as shown in Table 27.3, females in different reproductive categories are

Table 27.3 INVENTORY OF BREEDING FEMALES IN AN AVERAGE HERD PRACTISING 4-WEEK WEANING AND CULLING FEMALES AFTER AN AVERAGE OF FOUR LITTERS

\begin{tabular}{llcc}
\hline & Gilts $^{(\text {(u) }}$ & Sows & All females \\
\hline Unserved & $24 \%$ & $5 \%$ & $10 \%$ \\
Served, not yet farrowed & $61 \%$ & $75 \%$ & $72 \%$ \\
Farrowed, not yet weaned & $15 \%$ & $18 \%$ & $17 \%$ \\
Weaned, awaiting culling $^{(\text {b) }}$ & - & $2 \%$ & $1 \%$ \\
All classes & $29 \%$ & $71 \%$ & -
\end{tabular}

(a) Females aged over 6 months but not having weaned a litter (but see Table 27.1).

(b) Interval to culling should be minimal but market factors may make the percentage in this class higher thạn indicated 
enumerated and categorized, the inventory will rapidly show up bottlenecks in the breeding cycle.

There are four important aspects of the actual analysis of herd records to emphasize whether it is done manually or by computer:-

(a) Frequency of analysis, when done routinely, should be inversely proportional to herd size, with at least 25 female cycles (to smooth out random variations) but not more than 100 cycles included on each occasion. For example, records from 100 sow herds ought to be analysed at least every 2-3 months, 200 sow herds every month, and herds with more than 600 sows each week.

(b) The depth or detail to which analysis is carried out depends very much on herd circumstances, including the type as well as the size of the unit, and its past performance record. For example, a nucleus breeding herd with several sire and dam lines, and a large commercial herd with a poor reproductive performance record, may both benefit from frequent and very detailed record analyses. In the latter instance, however, once the problems have been brought under control the depth of analysis may be reduced. Sometimes, when characterizing a specific problem area by data analysis, or when looking for relationships between suspected causal factors and the problem, it is helpful to display the information visually in the form of histograms or charts. An example might be breakdown of returns to service into regular and irregular ones, as shown in Figure 27.2. Statistical methods will also be necessary in some instances, for example when conception rates achieved by different boars have to be examined for statistically significant differences.

(c) Speed of analysis (turn-round time) should be rapid, within 3-4 days if possible. In the past some farming organizations offered a

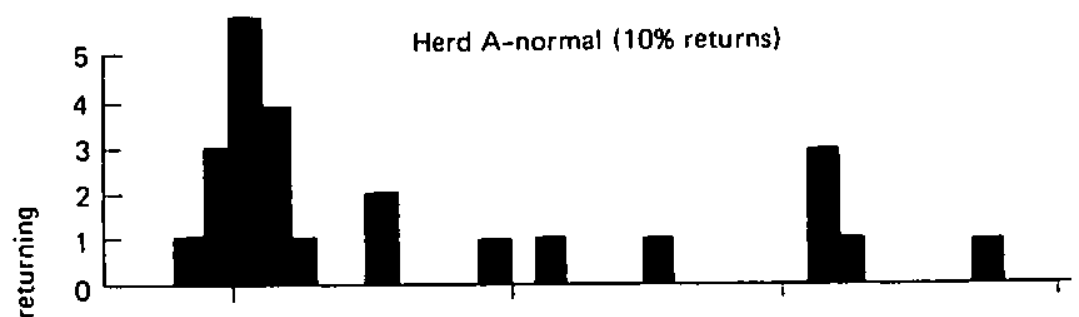

Herd B-abnormal (20\% returns)

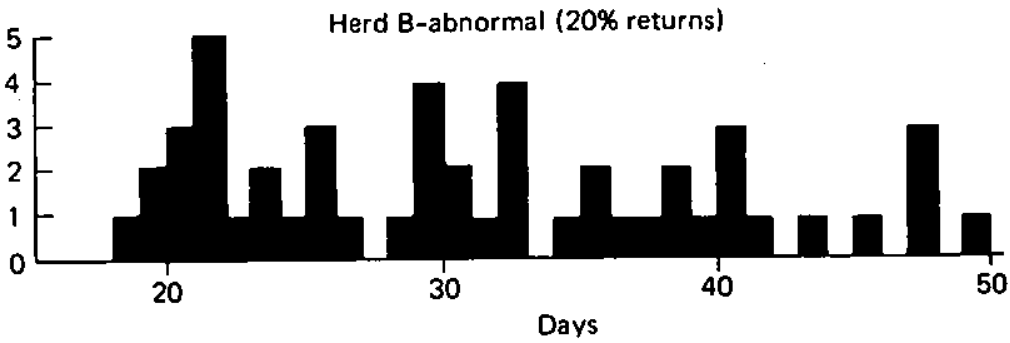

Figure 27.2 Histograms showing returns to service in two herds of comparable size. In the normal herd (A) returns occurred mainly at three weeks (19-23 days) or multiples thereof, whereas those in herd $B$ were much more irregular. Irregular returns are often indicative of a high level of embryonic mortality (i.e. with whole litter loss) 
computerized analysis service for herd records but the completion and return of results (by post) often took several weeks, by which time the value for herd health control was largely lost. It is helpful if routine veterinary visits can be arranged to coincide with arrival of the results of analysis; of course, this is no difficulty when private computing facilities are available.

(d) The manner in which the final analysis is displayed is of great importance; results should, above all, be readable and easily understood. Ideally, all the basic information relating to reproduction will be summarized on a single table, and any other data, such as those concerned with feed utilization and herd finance, will be put on other sheets. In addition to the performance parameters for the latest time period the values obtained in the previous one or two periods, together with the herd standards or targets for those parameters, should be easily visible for comparison. Some of the important parameters may also be displayed in graphic form, the graphs being prepared by hand or (as is now possible with some machines) by the computer's VDU or printer. Such graphs greatly facilitate monitoring of reproductive parameters.

\section{Monitoring reproductive parameters}

Monitoring is the regular observation of quantitative data emanating sequentially from a continuous production process. The purpose of monitoring is to detect any significant negative or undesirable deviations of the values from the predefined standard or acceptable range and, whenever such deviations occur, to carry out some form of remedial action.

In the manufacturing industries monitoring is not a new concept and is utilized routinely in many instances for quality control. In agriculture, however, the deliberate use of monitoring to supervise livestock performance is quite a recent innovation; appreciation of its value and a more scientific usage has been stimulated by growth in herd sizes and increasing remoteness between managers and their livestock. In the veterinary context effective monitoring of selected, key parameters undoubtedly constitutes a very logical basis for herd health control.

Probably the simplest and most useful monitoring system for use in the pig breeding herd involves use of control charts of the 'Shewhart' type (Shewhart, 1931). These consist of lengths of graph paper upon which successive results for a specific parameter are plotted against time, as they become available (see Figure $27.3 a$ ). Before results are actually plotted the standard or reference figure (derived from the average of at least 100 previous observations of the parameter, or from a knowledge of values in similar types of herd in the national population-see Table 27.2, column 2) is ruled as a horizontal line on the chart. 'Decision boundaries', sometimes referred to as 'action' or 'tolerance limits' (see Table 27.2, column 3), are also ruled on the paper, their purpose being to enable the observer to distinguish between significant changes in value of the monitored parameter and natural biological variations. 


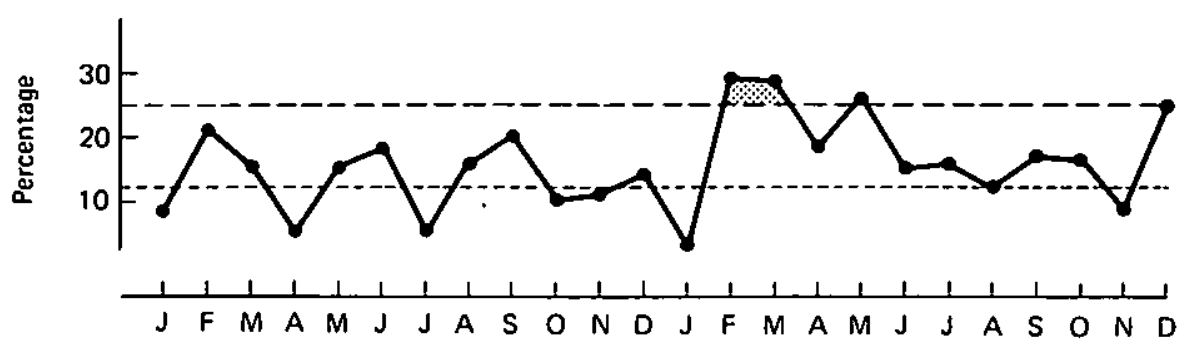

(a)

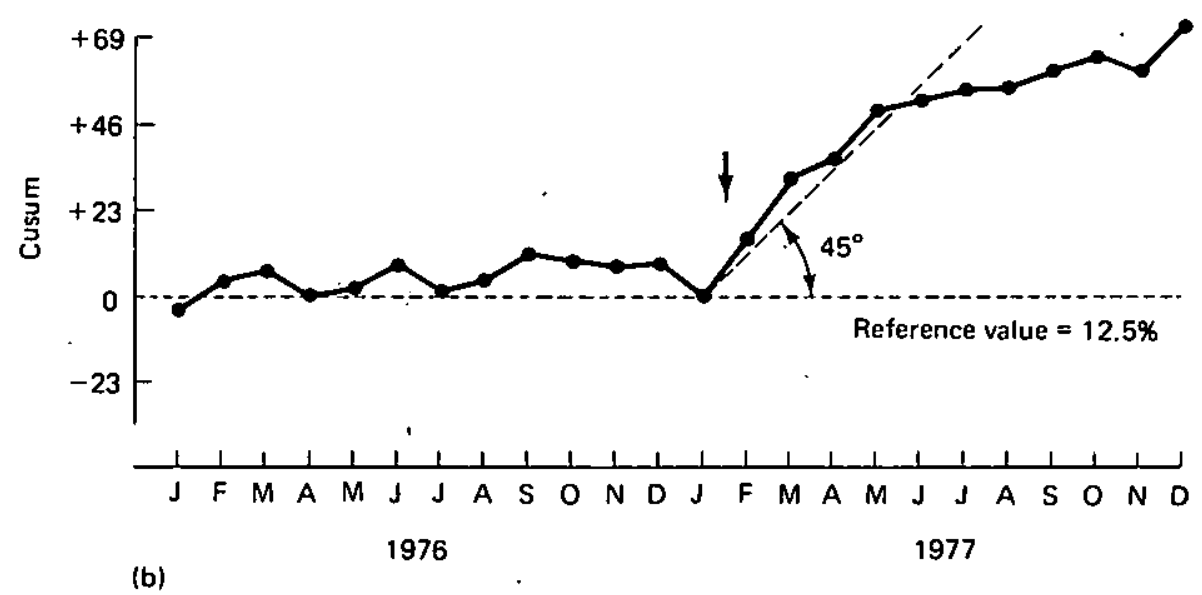

Figure 27.3 Examples of control charts used for monitoring reproductive parameters. (a) Shewhart chart showing a plot against time of the small litter index (litters with $\leqslant 8$ piglets born alive and dead). .... Decision boundary; .... Reference value. Note that the values in Feb-March 1977 fall slightly outside the decision boundary. (b) Cusum chart showing a plot of the cumulative sums of the small litter index. Note how the plot changes direction sharply in February 1977 and continues through the year indicating that a new trend, i.e. towards an increased percentage of smaller titters, has occurred. Because the change in direction, at least for the first four months, exceeds $45^{\circ}$, it is probably a highly significant one.

Decision boundaries may be set empirically, i.e. based on past experience, or they can be derived mathematically. The latter method can, however, be rather a complex business (see Page, 1961; Pepper, 1980; Sard, 1979). It requires a knowledge, firstly, of the standard deviation (SD) of the reference figure, and secondly, because averages of samples (e.g. those of monthly batches of sows which get mated or farrow) are scattered less widely about the overall population mean than are the individual values, the average sample size $(n)$ must be taken into account as well. A mathematically-derived decision boundary is, in fact, usually based on the standard error of the mean (SEM) of the average sample i.e.

$$
\mathrm{SEM}=\mathrm{SD} / \mathrm{V} n
$$

An important question to be asked when setting decision boundaries is "how often are we prepared to investigate false alarms?". If decision 


\section{2} Investigation and control of reproductive disorders in the herd

boundaries based on two SEMs are used then, on average, we must expect a false alarm (with values falling on only one side-the 'problem' side - of the mean) once in every 40 times. For important problems, such as abortions or returns to service, it might be sensible to set decision boundaries closer to the reference figure than this, e.g. at one SEM, in which case an unnecessary alarm might occur once in every six occasions. In practice, although knowledge of the SEM is a very valuable guide, rigid adherence to mathematical boundaries is not always wise. For one thing the size of the 'samples' (i.e. batch sizes) in a breeding herd varies from week to week and month to month, so an SEM-based boundary is seldom completely valid. Adjustment can, of course, be made according to experience and according to the sensitivity required for that particular parameter. Sometimes it is also useful to set 'warning limits' inside the decision boundaries on the Shewhart chart, in which case a warning on two or three consecutive occasions should be taken to constitute an alarm.

A method often used by farmers and others for 'smoothing out' unwanted random variations on control chart graphs is the 'moving' or 'rolling average', in which the values for the latest batch are, before averaging, weighted by adding values for a number of previous batches as well. The number of previous batches included in the rolling average varies but often 3, 6 or 12 consecutive months are taken. Although of some help, particularly for monitoring trends, rolling averages are inevitably retrospective, insensitive and rather cumbersome.

Whereas traditional Shewhart control charts are very effective for detecting large, abrupt changes in the value of a reproductive parameter, they are less so when changes are small, resulting from 'drift' in the value over a period of time. An alternative and more sensitive method for detecting such trends is the cumulative sum technique, and control charts incorporating this method are known as 'Cusum charts' (see Figure 27.3b). In practice the operation of Cusum charts is similar to that for Shewhart charts, the main difference being in the criteria for taking action. Essentially they consist of a continual plot against time of deviations of the cumulative value of the monitored parameter from its reference value $(k)$, the latter having been previously established in a manner similar to that used for the Shewhart chart. In the example shown in Figure $27.3 b$ the reference value $(\mathrm{k})$ has been set at $12.5 \%$. As the values $\left(x_{1}, x_{2}\right.$ and so on) for the batches in each successive time period become known the cumulative sums $\left(C_{1}, C_{2}\right.$ and so on) are calculated as follows:

$$
\begin{array}{ll}
\text { Period 1 } & C_{1}=x_{1}-\mathrm{k} \\
\text { Period 2 } & C_{2}=\left(x_{1}-\mathrm{k}\right)+\left(x_{2}-\mathrm{k}\right)=C_{1}+\left(x_{2}-\mathrm{k}\right) \\
\text { Period } 3 & C_{3}=C_{2}+\left(x_{3}-\mathrm{k}\right), \text { and so on. }
\end{array}
$$

On the Cusum chart it is changes in direction and slope of the plotted line which are important, rather than the position of the Cusum value above or below the reference value. In fact, even a small, non-significant, but consistent drift in the values of $x$ may mean that the plotted $C$ line strays far from the zero point, and eventually falls off the graph paper. The average slope of the line over a succession of plotted Cusum values is, therefore, very important, because any significant, persisting change in the 
mean value of the parameter under observation in relation to the set reference value (irrespective of the current position of $C$ on the chart) will appear as a significant change in the direction of the plot. Plateaux, on the other hand, indicate periods of stability.

The scale of the vertical in relation to the horizontal (time) axis on a Cusum chart is very important because it determines at what angle a change in slope of the Cusum plot is a significant one. This question is discussed in depth elsewhere (Page, 1961; Sard, 1979; Davies and Goldsmith, 1972) but basically, as with the Shewhart chart, scaling should be done with reference to the SEM (i.e. SD of $k / V n$ ). If, in drawing the Cusum chart, one time period equals one unit on the horizontal axis, and two SEMs of Cusum equal one unit on the vertical axis, then any change of $45^{\circ}$ or more will be highly significant, false alarms only occurring once in every 40 times. In practice smaller angle changes would probably be of considerable interest to the manager as well, and sophisticated methods (such as use of perspex $\mathrm{V}$-masks) for gauging importance of various angle changes are described in the references cited above.

A general question which needs careful consideration in relation to monitoring is which of the many possible reproductive parameters should be monitored by control chart procedures. Some lend themselves to it readily. Total litter size (piglets born alive and dead) is one obvious example, but inevitably it is retrospective, depending largely on numbers of ovulations and embryo deaths, both of which may have occurred months before the litter is born. By the time significantly low litter size values, especially short-term, non-repetitive ones (such as those caused by parvovirus-induced embryonic death) appear on the control chart it may be too late to take any effective action. Parameters more closely related to the actual determinative event include puberty (age at first mating), weaningto-service interval, abortions and stillbirths. Stillbirths may include some early neonatal deaths if farrowings are unattended, and this should be borne in mind when monitoring because the mechanisms of loss are often different. Although it is one of the more retrospective parameters, monitoring the small litter index (see Table 27.2 and Figure 27.3) is sometimes useful to gauge specifically litter size variability.

\section{Investigation and diagnosis of reproductive disorders}

Although monitoring is the key to detection of reproductive failure it does not, in itself, identify causes or bring about solutions. It must be considered, therefore, how a system to carry out these functions (when it is necessary) can be integrated into the herd management operations.

The veterinary role in target setting and monitoring has already been discussed and the logical extension to this is for services of the same veterinarian to be used routinely for investigation and problem solving as well. This not only enables reproductive and other disease problems to be dealt with promptly but it also provides a powerful means for overall improvement of herd health, performance and profitability. It does not, of course, eliminate the need for the services of specialists in other disciplines 
(e.g. nutrition, genetics, ventilation), or for occasional emergency veterinary visits. By virtue of training and historical association with the farm the practising veterinarian is usually the best qualified to give broad advice on matters of health and disease; he may have undergone species specialization and further training for this. Obviously such a service is not cheap and must give value for money, but studies on the economic effects of disease, including reproductive disorders, in pig herds, and on the benefits of effective control measures leave no doubt that veterinary involvement of the right calibre can be financially beneficial to most pig farmers (Ellis and James, 1979; Govier, 1978; Muirhead, 1978b, 1980).

\section{HERD VISITS AND CLINICAL EXAMINATIONS}

Veterinary involvement includes routine herd visits, the frequency and duration of these depending on herd type, size and expected economic benefit. Ideally visits should be timed to coincide with arrival of the herd record analysis and up-dating of the control charts. Muirhead (1980) gives detailed recommendations for the conduct of such visits, and his paper also provides examples of check lists (to ensure that important points are not overlooked), advice on educational programmes for the stockmen, and guidance on preparing written reports to maximize the impact of the visit.

Clinical signs of ill health include changes in appetite, body temperature, pulse rate and so on, but conventional manifestations like these are seldom apparent in the case of reproductive disorders; this is one reason why monitoring reproductive parameters is so important. If temporal correlations between changes in the various monitored parameters are evident they may provide valuable clues as to the nature of the problem (Wrathall, 1977). However, examination of the animals themselves and their environment is usually a necessary requisite for diagnosis once a problem has been detected.

A systematic tour of the herd, commencing with maiden gilts and recently weaned sows, and progressing stage by stage to lactating sows with their litters, is often helpful because problems manifesting at one stage of reproduction often have their origins in other stages. For example, inadequate feed levels during pregnancy and/or lactation in early parities (particularly the first) may lead to anoestrus or low conception rate in future cycles (Elsley, 1971; Akkermans, 1980). Recently attention has focused increasingly on changes in weight, body condition score, and fatness of sows because depletion of body fat in successive reproductive cycles can have important adverse effects on long-term reproductive performance (MAFF, 1978; Elsley, 1972; Deering, 1977; Whittemore, Franklin and Pearce, 1980). The problem of low energy reserves in sows may have been aggravated by progress over recent years in selecting for leanness in growing pigs; it probably means that more gilts now enter their first pregnancy with low levels of body fat, levels which are insufficient to tide them through several reproductive cycles, especially if they are in negative energy balance for extended periods.

Negative energy balance can arise not only from inadequate dietary energy but also from adverse climatic conditions, lack of bedding and 
immobility (e.g. confinement in stalls). Parasites (e.g. mange mites and helminth infestations) can exacerbate the effects. In addition to body condition and nutrition of the animals, therefore, an appraisal of environmental influences should be made; they include climatic and social factors and the construction and layout of buildings. High ambient temperatures, for example in summer, can seriously depress fertility in both boars and sows (Tomes and Nielsen, 1979; Wetteman, Wells and Johnson, 1979; Wrathall, 1975). Reproductive photoperiodicity associated with declining daylength is also being recognized increasingly as being responsible for depressed reproductive performance in the autumn (Hurtgen and Leman, 1980; 1981; Karlberg, 1980; Stork, 1979).

Social factors include the effects of pheromones and other male sexual stimuli on the onset of puberty, weaning-to-oestrus interval, intensity of oestrus, and conception rate in females (Brooks, 1978; Signoret, 1971; Kirkwood and Hughes, 1979; Hillyer, 1976; Hemsworth, Beilharz and Findlay, 1978). It is important, therefore, to assess how freely and effectively these stimuli operate in the herd. Recent work also suggests that the social environment during the rearing period as well as after puberty, is an influential determinant of normal sexual behaviour in boars (Hemsworth, Findlay and Beilharz, 1978; Hemsworth, 1980).

Building structure and design can have multiple influences on reproductive performance. They are sometimes effected via the climate or social environment, sometimes by effects on hygiene and spread of infections and sometimes by affecting the ease with which animals can be handled and supervised by the stockman. Matters of some concern, too, are the effects on sow performance of group size (e.g. at weaning) and of confining sows in stalls. The latter, in particular, is prone to depress manifestation of oestrus, making detection of sows which fail to conceive rather difficult (Jensen et al., 1970; England and Spurr, 1969; Laird and Walker-Love, 1972; Baxter, 1978).

The herd inspection provides opportunity for dialogue between the veterinarian and stockman regarding routine matters such as oestrus detection, feeding patterns, pregnancy diagnosis and farrowing procedures. Where a definite problem has been identified, however, attention has to be focused specifically onto that stage of reproduction in which the problem is manifested. For example, if there is an unacceptably high rate of regular, 3-week returns to service then a particularly careful examination of boars and mating procedures will be necessary. Similarly if the total litter size is normal but stillbirth rate is above the decision boundary then attention will focus on health and management of sows in late pregnancy and at farrowing.

In contrast to most other domestic animals special gynaecological examinations are used little in pigs, though they can be of value, particularly for older sows where the pelvic diameter is large enough for manual palpation of the genital organs per rectum. Ovarian abnormalities and pregnancy can be diagnosed in this way (Cameron, 1977; Meredith, 1977), and use of a speculum enables the vaginal lumen and cervix to be examined for inflammation, discharges, etc. Ultrasonic apparatus is quite widely used now for pregnancy diagnosis in pigs, and with Doppler types it is sometimes possible to make an assessment of foetal viability as well (Fraser, Nagaratnam and Callicott, 1971). 


\section{PATHOLOGICAL EXAMINATIONS}

There has been an unfortunate tendency to overlook pathology in the investigation of reproductive disorders. However, because it is concerned with detecting and describing disease lesions and with elucidating mechanisms (pathogenesis) of disease, it is a valuable discipline particularly for discerning links between causal factors and the presenting problems (Hall, 1976). In addition to the classical techniques of gross and histopathology used to study morphological lesions it is important to remember the very wide and increasing array of biochemical and endocrinological methods by which the functional pathology of reproduction can now be investigated.

Obviously selection of tissues or fluids for pathology must be guided by information gained at earlier stages of the investigation. If, for example, mated sows are returning to oestrus irregularly, and some actually reach full term but fail to farrow, then pathological (as well as clinical) investigations could be useful to elucidate, from among the following possibilities, what type(s) of problem it really is:

(a) failure by the stockman to observe sows in oestrus

(b) 'silent' (undetectable) oestrous cycles

(c) true anoestrus, with quiescent ovaries

(d) undetected abortions

(e) cystic ovarian disease

(f) embryonic death

(i) early death of the whole litter with irregular return or pseudopregnancy .

(ii) late death of the whole litter and retention of mummified foetuses in utero.

The pathological component of an investigation of this type of problem might include blood hormone assays as well as post-mortem studies of affected sows (Williamson, Hennessy and Cutler, 1980).

With regard to pregnancy disorders, investigations may be hindered by the fact that many disease processes go on in utero without visible external manifestations until, perhaps several weeks later, the diseased litter is aborted or farrowed. Pathological lesions of embryos and foetuses tend, moreover, to be rather different to those of postnatal life, and sequelae to death of the conceptus also vary considerably according to the stage of development (Wrathall, 1980a). Radiography is a useful technique for ascertaining age of death and skeletal lesions which preceded death in mummified and aborted foetuses. Where several foetuses are available from a litter it may also be possible to differentiate between simultaneous disease insults (e.g. maternal fever or transplacental toxic effects) and sequential ones where the disease spreads from foetus to foetus in utero, e.g. intrauterine virus infections (Wrathall, Bailey and Hebert, 1974).

Aborted foetuses are sometimes expelled without any obvious abnormalities other than subcutaneous congestion and haemolysis. On other occasions, however, examination shows that foetal disease and death preceded the abortion. Careful pathological study may, therefore, enable a distinction to be made between abortions of the maternal failure type and 
those of the embryonic failure type (Wrathall, 1977; 1980b). When freshly dead foetuses, stillbirths, or early neonatal deaths constitute a major component of a problem these may be subjected to more thorough examinations. First, gestational age should be established (from the service date), then body size and possibly organ weights may be taken for comparison with the appropriate standards for normal foetuses or piglets of the same gestational age. Such standards are especially valuable in foetal pathology because abnormalities of growth are relatively common in prenatal diseases (Langley, 1971; Wrathall, 1977).

\section{LABORATORY TESTS}

Innumerable special tests are applicable to reproductive failure investigations, but it would be inappropriate to discuss them in detail here. Their main purpose is to finally identify specific causal agents or aetiological factors, and they should, ideally, be used only when, on the basis of previous investigations, a direct causal relationship is strongly suspected, or when active measures to control a problem would be unjustified without greater certainty as to its aetiology. It will be clear, therefore, that laboratory tests are not invariably necessary (or appropriate) for the control of reproductive disorders. For example, when climatic or social factors are suspected, valid confirmation may only come after corrective action has been applied and a satisfactory response obtained. Too much reliance on specific tests, e.g. those for infectious organisms, toxins or nutrient deficiencies, is to be avoided because even a positive result may actually be the wrong answer as far as the real herd problem is concerned. This is especially liable to happen if preliminary investigations have been too superficial.

\section{Prognosis}

Before deciding upon active control measures it is important first to make a forecast as to the probable duration and chances of recurrence of the problem, and also the degree to which overall herd performance is liable to be affected in the future. Of course such forecasts do rely heavily upon a knowledge of the performance deficits so far, and also upon a correct diagnosis. However, assuming these, the prognosis should ideally be converted into monetary terms to show how the problem might affect future profitability. This can be done relatively simply in terms of 'opportunity piglet' values ('lost opportunity of production'-Govier, 1978) which assumes that overheads are approximately the same however many piglets are produced, i.e.

Cost of problem $=$ deficit of liveborn piglets $\times$ value of a piglet (about $f 20$ at the time of writing).

Although such forecasts inevitably entail some guesswork, they do provide a good foundation for deciding upon the right kind of control action to take. 


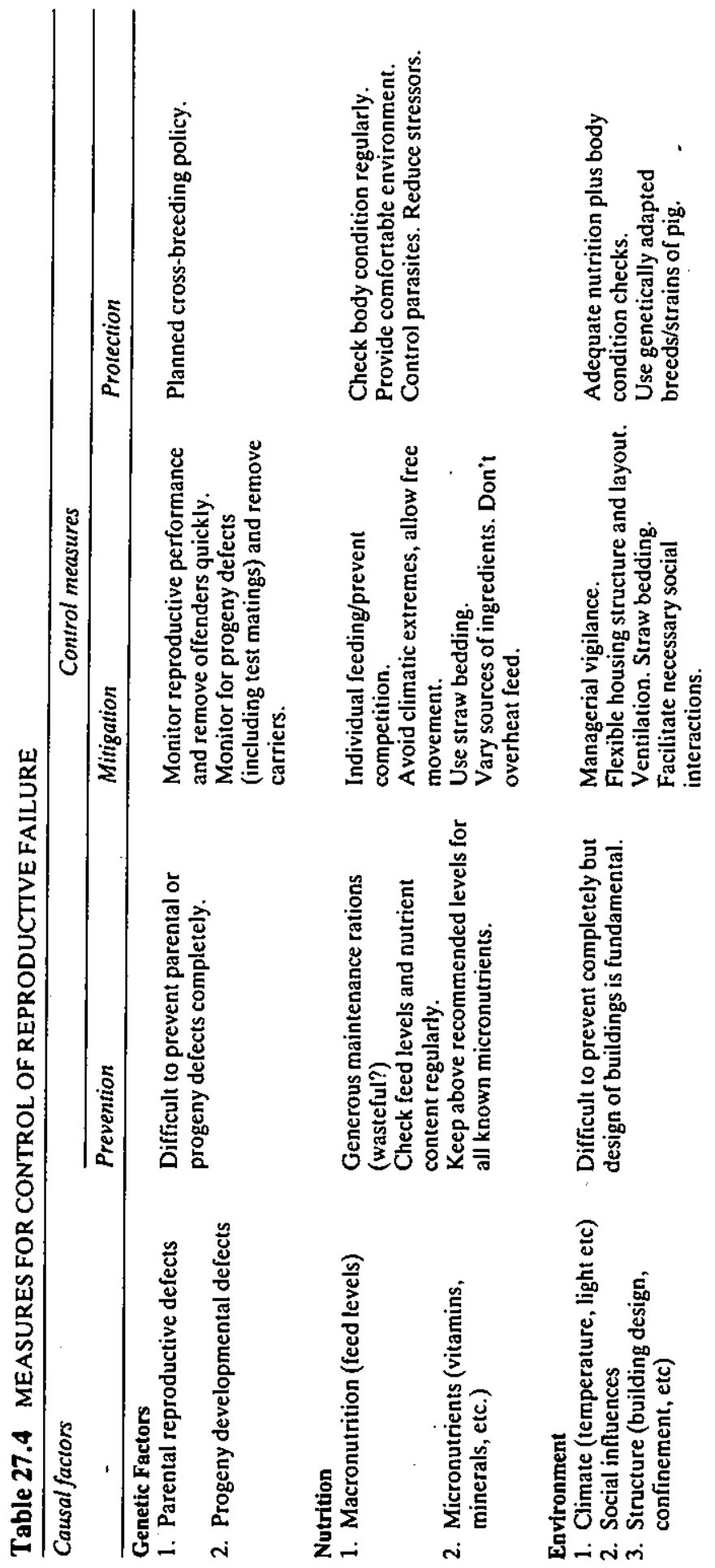



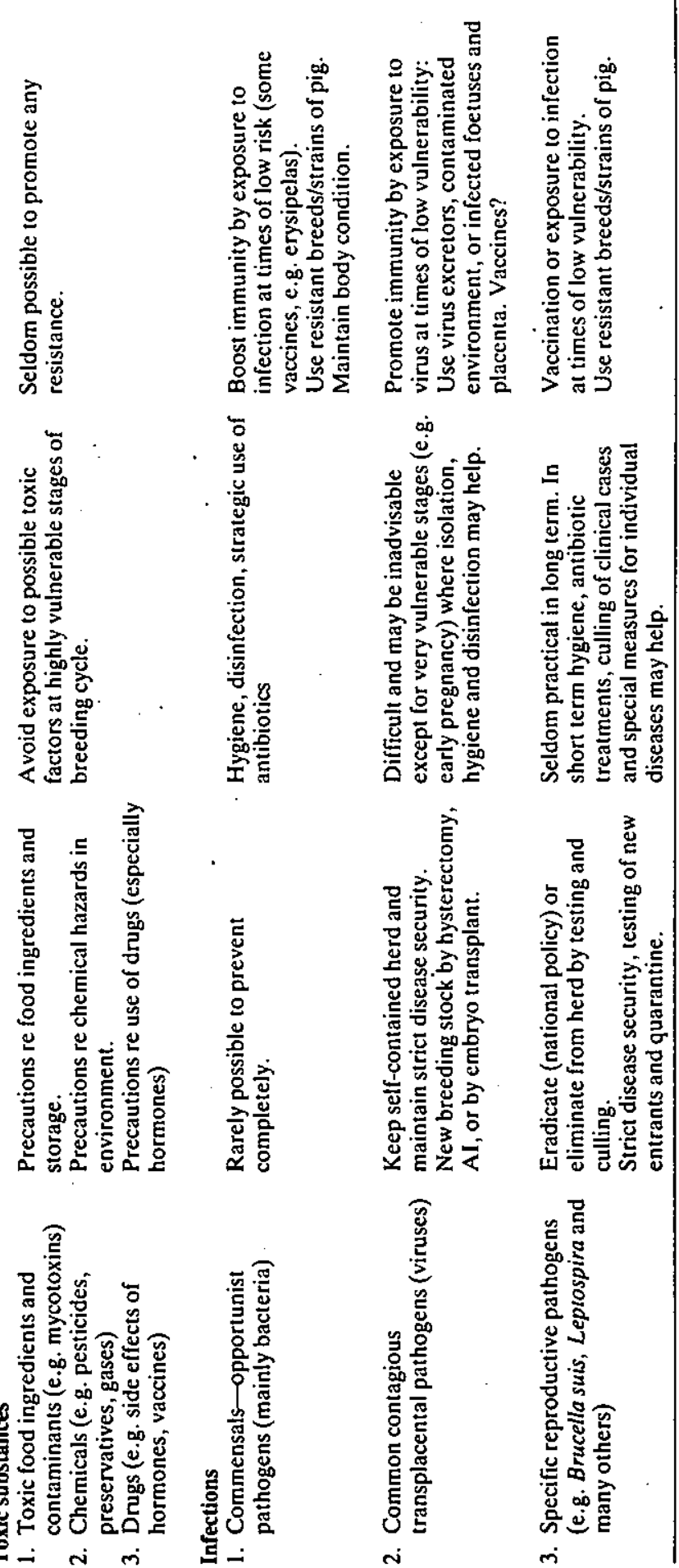


\section{Principles for the application of control measures}

Measures used to control reproductive disorders fall into three main categories:

(a) Prevention: elimination of the causal factor from the herd, or prevention of its entry.

(b) Mitigation: reduction of the amount (weight) of the causal factor which is encountered by vulnerable animals in the herd.

(c) Protection: promotion of resistance to the causal factor in vulnerable animals.

In view of the great multiplicity of causal factors and types of control action for reproductive disorders, it would be inappropriate to discuss these in detail here. Table 27.4 attempts to set out in a simplified manner some of the measures which may be used for control once the aetiology has been established. More detailed coverage may be found in other texts (e.g. Dunne and Leman, 1975; English, Smith and MacLean, 1977; Wrathall, 1975).

It is worth mentioning that positive control action is not invariably needed. For example, with certain infectious disorders which act early in pregnancy and lead to early embryonic death, the problem may not become apparent for many weeks and by the time it is detected a strong immunity may have already developed in all the adult breeding stock. If serological tests confirm this then further action may be superfluous. Active control measures may be ruled out in other instances for economic reasons, the cost of applying them being liable to exceed the effect the problem is having on profitability. Ultimately, of course, this concept applies to every aspect of control, whether it is specific action for a particular disorder or the overall attempts by management to improve herd performance. The aim is to achieve a right balance where the input costs of control measures approximate to, but do not exceed, the level where financial return from the action disappears. With regard to the overall control of reproductive failure, as outlined in this chapter, most herds have a long way to go before the law of diminishing returns will even start to operate.

\section{References}

AKKERMANS, J.P.W.M. (1980). Recent findings on fertility disorders in the pig. Fortschr. Vet. Med. 30, 95-98

BAXTER, S.H. (1978). Some general principles of housing for reproductive efficiency in pigs. In The Veterinary Annual, 18th Edition. (C.S. Grunsell and F.W.G. Hill, Eds.), pp. 126-133. Bristol, John Wright and Sons

BROOKS, P.H. (1978). Early sexual maturity and mating of gilts. $A D A S$ Quart. Rev. 30, 139-152

CAMERON, R.D.A. (1977). Pregnancy diagnosis in the sow by rectal examination. Aust. Vet. J. 53, 432-435 
DAVIES, O.L. and GOLDSMITH, P.L. (1972). Statistical Methods in Research and Production. 4th Edition. London and New York, Longman Group Ltd.

DEERING, J. (1977). Condition scoring sows. Pig. Fmg. 25, 57-58

DUNNE, H.W. and LEMAN, A.D. (1975). Diseases of Swine. 4th Edition. Ames, Iowa, The Iowa State University

ELLIS, P.R. and JAMES, A.D. (1979). The economics of animal health: (2) Economics in farm practice. Vet. Rec. 105, 523-526

ELSLEY, F.W.H. (1971). Recent advances in sow nutrition and their application in practice. ADAS Quart. Rev. 1, 30-38

ELSLEY, F.W.H. (1972). Some aspects of productivity in the sow. In The Improvement of Sow Productivity (A.S. Jones, V.R. Fowler and J.C.R. Yeats, Eds.), pp. 71-87. Aberdeen, Rowett Research Institute

ENGLAND, D.C. and SPURR, D.T. (1969). Litter size of swine confined during gestation. J. Anim. Sci. 28, 220-223

ENGLISH, P.R., SMITH, W. and MACLEAN, A. (1977). The Sow-Improving her Efficiency. Ipswich, Farming Press Ltd.

FRASER, A.F., NAGARATNAM, V. and CALLICOTT, R.B. (1971). The comprehensive use of Doppler ultra-sound in farm animal reproduction. Vet. Rec. 88, 202-205

GOVIER, R.J. (1978). The economics of pigs disease: A method of calculating the on farm cost. Pig Vet. Soc. Proc. 2, 101-111

HALL, S.A. (1976). Problems, diseases and diagnoses: A personal view. Vet. Rec. 98, 379-381

HEMSWORTH, P.H. (1980). The social environment and the sexual behaviour of the domestic boar. Appl. Anim. Ethol. 6, 306

HEMSWORTH, P.H., BEILHARZ, R.G. and FINDLAY, J.K. (1978). The importance of the courting behaviour of the boar on the success of natural and artificial matings. Proc. Aust. Soc. Anim. Prod. 12, 247

HEMSWORTH, P.H., FINDLAY, J.K. and BEILHARZ, R.G. (1978). The importance of physical contact with other pigs during rearing on the sexual behaviour of the male domestic pig. Anim. Prod. 27, 201-207

HILLYER, G.M. (1976). An investigation using a synthetic porcine pheromone and the effect on days from weaning to conception. Vet. Rec. 98, 93-94

HURTGEN, J.P. and LEMAN, A.D. (1980). Seasonal influence on estrous activity in sows and gilts. $J$. Am. vet. med. Ass. 176, 119-123

HURTGEN, J.P. and LEMAN, A.D. (1981). Effect of parity and season of farrowing on the subsequent farrowing interval of sows. Vet. Rec. 108, 32-34

JENSEN, A.H., YEN, J.T., GEHRING, M.M., BAKER, D.H., BECKER, D.E. and HARMON, B.G. (1970). Effects of space restriction and management on pre- and postpubertal response of female swine. J. Anim. Sci. 31, 745-750

KARLBERG, K. (1980). Factors affecting postweaning oestrus in the sow. Nord. Vet. Med. 32, 185-193

KIRKWOOD, R.N. and HUGHES, P.E. (1979). The influence of age at first boar contact on puberty attainment in the gilt. Anim. Prod. 29, 541-548

LAIRD, R, and WALKER-LOVE, J. (1972). A comparison of the performance of sows housed in sow stalls or in yards during pregnancy. Proc. 54th Meet. Br. Soc. Anim. Prod., 147 
LANGLEY, F.A. (1971). The perinatal postmortem examination. J. clin. Path. 24, 159-169

MEREDITH, M.J. (1977). Clinical examination of the ovaries and cervix of the sow. Vet. Rec. 101, 70-74

MINISTRY OF AGRICULTURE, FISHERIES AND FOOD (1978). Nutrient allowances for pigs. Advisory Paper No. 7

MINISTRY OF AGRICULTURE, FISHERIES AND FOOD (1979). Pig health and production recording. Booklet 2075

MUIRHEAD. M.R. (1978a). Constraints on productivity in the pig herd. Vet. Rec. 102, 228-231

MUIRHEAD. M.R. (1978b). The economics of pig disease: The veterinary surgeon's angle. Pig Vet. Soc. Proc. 2, 113-122

MUIRHEAD, M.R. (1980). The pig advisory visit in preventive medicine. Vet. Rec. 106, 170-173

PAGE, E.S. (1961). Cumulative Sum Charts. Technometrics 3, 1-9

PEPPER, T.A. (1980). Observations on the use of a computer program for analysing pig breeding and performance records. Pig Vet. Soc. Proc. 6, 57-63

PEPPER, T.A., BOYD, H.W. and ROSENBERG, P. (1977). Breeding record analysis in pig herds and its veterinary applications. 1: Development of a program to monitor reproductive efficiency and weaner production. $V e t$. Rec. 101, 177-180

RODEFFER, H.E., LEMAN, A.D. and MUELLER, A.G. (1975). Development of a record system for measuring swine breeding herd efficiency. J. Anim. Sci. 40, 13-18

SARD, D.M. (1979). Dealing with data: The practical use of numerical information - (14) Monitoring changes. Vet. Rec. 105, 323-328

SHEWHART, W.A. (1931). The Economic Control of the Quality of the Manufactured Product. New York, Macmillan

SIGNORET, J.P. (1971). The reproductive behaviour of pigs in relation to fertility. Vet. Rec. 88, 34-38

STORK, M.G. (1979). Seasonal reproductive inefficiency in large pig breeding units in Britain. Vet. Rec. 104, 49-52

SUNDGREN, P.E. VAN MALE, J.P., AUMAITRE, A., KALM, E. and NIELSEN, H.E. (1980). Sow and litter recording procedures. Report of a working party of the EAAP Commission on pig production. Livest. Prod. Sci. 7, 394-401

TOMES, G.J. and NIELSEN, H.E. (1979). Seasonal variations in the reproductive performance of sows under different climatic conditions. Wld. Rev. Anim. Prod. 15, 9-19

WALTON, J.R., MARTIN, J.W. and WARD, W.R. (1980). The collection and use of data on a pig farm. Pig Vet. Soc. Proc. 6, 23-28

WETTEMANN, R.P., WELLS. M.E. and JOHNSON, R.K. (1979). Reproductive characteristics of boars during and after exposure to increased ambient temperature. J. Anim. Sci. 49, 1501-1505

WHITTEMORE, C.T., FRANKLIN, M.F. and PEARCE, B.S. (1980). Fat changes in breeding sows. Anim. Prod. 31, 183-190

WILLIAMSON, P., HENNESSY, D.P. and CUTLER, R. (1980). The use of progesterone and oestrogen concentrations in the diagnosis of pregnancy, and in the study of seasonal infertility in sows. Aust. J. agric. Res. 31, 233-238 
WILSON, M.R., McMILLAN, I. and SWAMINATHAN, S.S. (1980). Computerized health monitoring in swine health management. Pig Vet. Soc. Proc. 6, 64-71

WRATHALL, A.E. (1975). Reproductive Disorders in Pigs. Slough, UK, Commonwealth Agricultural Bureaux

WRATHALL, A.E. (1977). Reproductive failure in the pig: Diagnosis and control. Vet. Rec. 100, 230-237

WRATHALL, A.E.(1980a). Mechanisms of porcine reproductive failure. In The Veterinary Annual, 20th Edition. (C.S.G. Grunsell and F.W.G. Hill, Eds.), pp. 265-274. Bristol, John Wright and Sons

WRATHALL, A.E. (1980b). Ovarian disorders in the sow. Vet. Bull. 50, 253-272

WRATHALL, A.E., BAlLEY, J. and HEBERT, C.N. (1974). A radiographic study of development of the appendicular skeleton in the foetal pig. Res. Vet. Sci. 17, 154-168 